\title{
Italy's largest snake: Redescription of Palaeophis oweni from the Eocene of Monte Duello, near Verona
}

Georgios L. Georgalis, Letizia Del Favero, and Massimo Delfino

Acta Palaeontologica Polonica 65 (3), 2020: 523-533 doi:https://doi.org/10.4202/app.00711.2019

We here redescribe Palaeophis oweni, an almost neglected species of palaeophiid snakes from the Eocene of Monte Duello, northeastern Italy. Despite having been described since the 19th century and being the only known named species of its genus from Mediterranean Europe, $P$. oweni has so far received only minor and sporadic attention in the literature. The only as yet available information for this species was the original lithograph accompanying its brief, 1881 description. We here provide photographs and detailed description of the type and only known material for the first time, designate a lectotype, and clarify certain nomenclatural issues, as well as inaccuracies in the original lithograph. We distinguish certain features in its vertebral anatomy that allow us to treat $P$. oweni as a valid species and provide an emended diagnosis. Nevertheless, we highlight that a comprehensive reassessment of the nominal species of Palaeophis from the Eocene of the United Kingdom is essential in order to decipher with certainty the validity and distinctiveness of the Italian form. Palaeophis oweni represents the largest snake known from the Italian fossil record.

Key words: Squamata, Serpentes, Palaeophis, Paleogene, Europe, Italy.

Georgios L. Georgalis [georgios.georgalis@unito.it], Dipartimento di Scienze della Terra, Università di Torino, Via Valperga Caluso 35, 10125 Torino, Italy. Letizia Del Favero [letizia.delfavero@unipd.it], Museo di Geologia e Paleontologia, Centro di Ateneo per i Musei, via Giotto 1, 35121, Padua, Italy. Massimo Delfino [massimo.delfino@unito.it], Dipartimento di Scienze della Terra, Università di Torino, Via Valperga Caluso 35, 10125 Torino, Italy; and Institut Català de Paleontologia Miquel Crusafont, Universitat Autònoma de Barcelona, Edifici ICTAICP, Carrer de les Columnes s/n, Campus de la UAB, 08193 Cerdanyola del Vallès, Barcelona, Spain.

This is an open-access article distributed under the terms of the Creative Commons Attribution License (for details please see creativecommons.org), which permits unrestricted use, 
distribution, and reproduction in any medium, provided the original author and source are credited.

FoF Full text $(35,834.5 \mathrm{kB})$ 